\title{
ISOLAMENTO DE Mycoplasma spp. NO TRATO REPRODUTIVO DE PEQUENOS RUMINANTES NO SEMIÁRIDO PARAIBANO
}

\author{
(Isolation of mycoplasma spp. in the reproductive tract of small ruminants in the \\ semi-arid region of Paraíba)
}

\begin{abstract}
Aline Guedes Mamede Moraes, Aline Antas Cordeiro, Natanael Souza Silva, Ana Claudia Campos, Marcia Almeida Melo, Edisio Oliveira Azevedo
\end{abstract}

\begin{abstract}
${ }^{1}$ Correspondência: alineguedesmamede@gmail.com
RESUMO: Pesquisou-se Mycoplasma spp. em amostras de suabes vaginais e prepuciais de 154 animais, sendo 61 caprinos e 93 ovinos, oriundos de quatro rebanhos localizados nos municípios de Patos, São José do Bonfim, São José de Princesa e Soledade, estado da Paraíba. Foram coletados dados sobre o histórico reprodutivo e realizado o exame específico do sistema genital. Não foram observadas lesões na genitália externa nos animais estudados. $O$ isolamento do Mycoplasma spp. foi realizado em meio Hayflick modificado, líquido e sólido. Dentre as amostras analisadas, duas (1,3\%) apresentaram crescimento de Mycoplasma spp., sendo uma na espécie caprina e outra em um ovino pertencentes a ao rebanho de Patos e São José do Bonfim, respectivamente. Confirmou-se a presença de Mycoplasma spp. no trato reprodutivo de pequenos ruminantes na região do semiárido paraibano, no entanto, não houve associação do isolamento de micoplasmas com lesões na genitália externa. O presente trabalho é o primeiro relato do isolamento deste agente em genitálias de caprinos e ovinos na região Nordeste do Brasil.
\end{abstract}

Palavras-chave: caprinos; micoplasmas; ovinos; reprodução

ABSTRACT: Samples of Mycoplasma spp. in vaginal and preputial swabs of 154 animals were researched, being 61 goats and 93 sheep, originated from four herds located in the municipalities of Patos, São José do Bonfim, São José de Princesa and Soledade, in the state of Paraíba. Data on the reproductive history was collected, and the specific exam of the genital system was carried out. External lesions of the external genitalia were not observed in the animals studied. The isolation of the Mycoplasma spp. was carried out on liquid and solid modified Hayflick's media. Within the analyzed samples, two $(1,3 \%)$ presented growth of Mycoplasma spp., being one in a goat and one in a sheep belonging to the herd from Patos and São José do Bonfim, respectively. It was confirmed the presence of Mycoplasma spp. in the reproductive tract of small ruminants in the semi-arid region of Paraíba, however, there was no association of the isolation of the mycoplasmas with lesions of the external genitalia. The present work is the first report of the isolation of this agent in goats and sheep's genitalia in the northeastern region of Brazil.

Key Words: goats; mycoplasmas; sheeps; reproduction 
INTRODUÇÃO

A associação de microrganismos da classe dos Mollicutes com desordens reprodutivas em caprinos e ovinos não é frequentemente relatada.

Mycoplasma bovigenitalium está relacionado com casos de vulvovaginitis e desordens reprodutivas na Austrália, Estados Unidos, Índia, Inglaterra, França e Nigéria. Inoculações experimentais causaram um quadro clínico de vulvovaginite granular, caracterizada por edema de vulva, descargas uterinas, vulvitis, vaginite, cervicite e endometrite. Outras espécies foram isoladas do trato reprodutivo de pequenos ruminantes com circunstancial patogênese. Neste contexto, estão incluídos: M. mycoides subps. mycoides, M. mycoides subsp. capri, M. agalactiae, M. arginini, $M$. alkalesecens (Kapoor et al., 1984; Ak et al., 1995; Nicholas et al., 1999).

No Brasil o principal agente da classe dos Mollicutes envolvido em problemas reprodutivos é $0 \quad M$. agalactiae, responsáveis por casos de aborto em caprinos, no entanto, um trabalho mais aprofunddado relacionando a infecção com outros disturbios reprodutivos ainda não foi realizado. $A$ agalaxia contagiosa $(A C)$ foi diagnosticada pela primeira vez no estado da Paraíba em 2001, onde posteriormente a doença se disseminou para outros estados através do trânsito de animais destinados ao melhoramento genético, sendo diagnosticados casos da enfermidade em Pernambuco e Rio Grande do Norte (Azevedo et al., 2006).

Contudo, pode-se afirmar que a AC atingiu um caráter endêmico na região do Semiárido paraibano, visto que tem sido comum a ocorrência de casos em diversos rebanhos, com taxas de prevalência que atingem aproximadamente $\quad 70 \% \quad$ em determinadas microrregiões (Alcântara, 2010).
As micoplasmoses causam sérias perdas econômicas associadas com poliartrites, mastites, agalaxia, conjuntivite, pneumonias, nascimento de crias com sinais clínicos ou mesmo o desenvolvimento destes nos primeiros dias de vida e falhas reprodutivas. Esta última pode envolver repetição de cio, vulvovaginite granular, infertilidade e abortos. Visando avaliar o envolvimento desses agentes com disturbios reprodutivos, o objetivo desse estudo foi verificar a ocorrência de Mycoplasma spp. no trato reprodutivo de caprinos e ovinos procedentes da região semiárida do estado da Paraíba, Nordeste do Brasil.

\section{MATERIAL E MÉTODOS}

Foram utilizados 154 animais de idades variadas, sendo 61 caprinos (7 machos/54 fêmeas) e 93 ovinos (11 machos/82 fêmeas), oriundos de quatro rebanhos localizados nos municípios de Patos, São José do Bonfim, São José de Princesa e Soledade, estado da Paraíba. As propriedades foram escolhidas por conveniência, a partir do relato de desordens reprodutivas, como abortos e mortes neonatais.

Os animais passaram por uma avaliação clínica, onde foram obtidas informações sobre 0 histórico reprodutivo e em seguida examinados individualmente. Nas fêmeas, o exame do aparelho genital consistiu na inspeção direta da vulva, vestíbulo e fundo da vagina e entrada da cérvix com o auxílio de espéculo e lanterna para melhor visualização. Nos machos, realizou-se inspeção e palpação nos testículos, epidídimos, escroto, prepúcio e pênis. Atentou-se também para presença de sinais clínicos associados a $A C$, doença endêmica na região.

Antes da coleta, os animais foram submetidos à higiene da região externa da vulva ou prepúcio com papel toalha. Para obtenção do material biológico a 
vulva foi aberta com deslocamento dos lábios vulvares e nos machos foi realizada tração do prepúcio com posterior exposição da glande. Friccionou-se o suabe na parede do vestíbulo vulvar e na mucosa da glande peniana, sequencialmente os suabes foram transferidos para tubos estéreis contendo solução glicerinada a $50 \%$ com $2000 \mathrm{UI} / \mathrm{mL}$ de penicilina.

Todo material coletado foi mantido refrigerado a $4^{\circ} \mathrm{C}$ e posteriormente enviado ao Laboratório de Vacinas e Diagnóstico (LAVADI-CSTR/UFCG), onde foram mantidas a $-20^{\circ} \mathrm{C}$ até $\mathrm{O}$ momento do processamento. As amostras foram semeadas em meio Hayflick modificado líquido e sólido, conforme descrito por Azevedo et al. (2006).

\section{RESULTADOS E DISCUSSÃO}

Em três propriedades estudadas, os animais eram destinados ao consumo e comercializados para complementar a renda familiar, havendo fluxo constante de animais. Na outra propriedade, os animais eram destinados à produção leiteira, sendo monitorada regularmente por médico veterinário. Em todas as propriedades os animais que apesentavam algum problema reprodutivo eram medicados e posteriormente comercializados.

Foi realizado cultivo de 54 amostras de suabe vaginal caprino e 82 de ovino, destas, apenas duas $(1,3 \%)$ foram positivas para Mycoplasma spp., sendo uma da espécie caprina, do rebanho de Patos, e a outra da espécie ovina, de São José do Bonfim. Observou-se no cultivo a presença de colônias com aspecto de "ovo frito", filmes e manchas. Nenhum dos animais no exame clínico exibiu lesões na genitália ou sinais clínicos associados a AC. Resultados semelhantes foram obtidos por Rizzo et al. (2011), onde de 18 amostras de muco vaginal ovino, em seis (33\%) foi possível o isolamento, entretanto, os autores não associaram a presença desses agentes com distúrbios reprodutivos. Os mesmos autores obtiveram sucesso na detecção de micoplasma e ureaplasma em material clínico do trato reprodutivo de fêmeas da espécie caprina, utilizando primers genéricos da região $16 \mathrm{~S}$ rRNA, por meio da reação em cadeia da polimerase (PCR), estes pesquisadores detectaram ainda micoplasmas anteriormente descritos como espécieespecíficos, envolvidos em infecções em hospedeiros não específicos.

Estes achados sugerem que a infecção está presente nos pequenos ruminantes e que a manutenção de animais portadores assintomáticos pode contribuir para a permanência deste micro-organismo na região. O papel epidemiológico desses animais ainda não está esclarecido, embora rebanhos livres de infecção possam se infectar através da introdução dos mesmos. Por isso, medidas preventivas, como a quarentena, desinfecção das instalações, vacinação e realização periódica de testes sorológicos visando à manutenção de rebanhos livres devem ser realizados (Azevedo et al., 2006). Bem como, determinar o real potencial desses animais como reservatório e avaliar se esta via é passível de transmissão aos reprodutores através da monta natural.

A presença de micoplasmas no sistema reprodutivo e sua associação com patologias foi considerada controversa até alguns anos atrás, pois animais sadios eram encontrados como portadores destes micro-organismos. Os dados de infecções naturais e experimentais, causando abortos e infertilidade em bovinos, além de surtos da síndrome de vulvovaginite granular comprovaram sua importância como patógenos do sistema reprodutivo (Rocha, 2009). 
Além de ser um dos agentes responsáveis pela $A C, \circ M$. agalactiae está relacionado com casos espontâneos de vulvovaginite granular (Gil et al., 2003) e lesões características de grânulos do tamanho de "cabeça de alfinete" amarelo-esbranquiçado e translúcido dispostos de forma linear próximo ao clitóris, hiperemia de mucosa e edema, além da presença de exsudato purulento em cabras (Singh et al., 1974). Em carneiros infectados experimentalmente pôde-se isolá-lo no sangue, sêmen, vesícula seminal, testículos e epidídimos, observando mudanças nas características dos ejaculados e alterações degenerativas nos órgãos necropsiados (Ak et al., 1995).

Um estudo realizado por De $\mathrm{La} F e$ et al. (2009) conseguiram isolar $M$. agalactiae do sêmen de caprinos na Espanha, mas não ficou esclarecido se a via venérea era passível de transmissão do microorganismo. Sua importância em falhas reprodutivas e na expansão da enfermidade entre os rebanhos de caprinos e ovinos na região Nordeste do Brasil é desconhecida. Sendo observadas alterações na qualidade do sêmen, transmissão transplacentária e abortos em animais naturalmente infectados (Alves et al., 2013; Silva et al., 2013; Silva et al., 2014). O diagnóstico restrito a poucos laboratórios qualificados pode ser 0 desencadeante do pouco relato na literatura do envolvimento de micoplasmas com disturbios reprodutivos em animais domésticos.

\section{CONCLUSÃO}

Confirmou-se a presença de Mycoplasma spp. no trato reprodutivo de pequenos ruminantes na região do Semiárido paraibano, no entanto, não houve associação do isolamento de micoplasmas com lesões na genitália externa. O presente trabalho é o primeiro relato do isolamento deste agente em genitálias de caprinos e ovinos na região Nordeste do Brasil.

\section{NOTAS INFORMATIVAS}

Reservado ao parecer CEUA.

\section{REFERÊNCIAS}

AK, K.; AK, S.; GUREL, A. et al. Experimental studies on the effects of Mycoplasma agalactiae on the spermatozoa and genital organs of rams. Pendik Vet. Mikrobiyol. Derg., v.26, n.2, p.139-155, 1995.

ALCÂNTARA, M.D.B. Soroprevalência da agalaxia contagiosa e vacinação experimental em caprinos. 2010. Patos, 52f. Dissertação (Mestrado em Medicina Veterinária) - Curso de Pósgraduação em Medicina Veterinária, Universidade Federal de Campina Grande.

ALVES, B.H.L.S.; SILVA, J.G.; MOTA, A.R. et al. Mycoplasma agalactiae in semen and milk of goat from Pernambuco State, Brazil. Pesq. Vet. Bras., v.33, n.11, p.1309-1312, 2013.

AZEVEDO, E.O.; ALCÂNTARA, M.D.B.; NASCIMENTO, E.R. et al. Contagious agalactia by Mycoplasma agalactiae in small ruminants in Brazil: first report. Braz. J. Microbiol., v.37, p.576-581, 2006.

DE LA FE, C.; AMORES, J.; MARTIN, A.G. et al. Mycoplasma agalactiae detected in the sêmen of goat bucks. Theriogenology, v.72, p.1278-1281, 2009.

GIL, M.C.; PEÑA, F.J.; MENDOZA, J.H. et al. Genital lesions in an outbreak of caprine contagious agalactiae caused by Mycoplasma agalactiae and 
Mycoplasma putrefaciens. J. Vet. Med.

Series B., v.50, n.10, p.484, 2003.

KAPOOR, S.G.; SINGH, P.P.; PATHAK,

R.C. Prevalence of

mycoplasma/acholeplasma in the genital tract of sheep. The Indian Journal Animal Sciences, v.54, n.7, p.553-556, 1984.

NICHOLAS, R.A.J.; WESSELS, M.; ORME, P.K. et al. Isolation of Mycoplasma ovine/caprine serogroup 11 from infertile sheep in Britain. The Vetertinary Record, v.145, n.9, p.434435, 1999.

RIZZO, H; MEIRA JUNIOR, E.B.S.; OLIVEIRA, R.C. et al. Isolamento e PCR para detecção de Mollicutes em muco vaginal e sua associação com problemas reprodutivos em ovinos criados na região de Piedade, São Paulo, Brasil. Ciência Rural, v.41, n.2, p.324-329, 2011.

ROCHA, J.M.N. Micoplasmose em bovinos de aptidão leiteira: fatores predisponentes para a ocorrência e manifestação da síndrome da vulvovaginite granular. 2009. Goiânia, 134f. Tese (Doutorado em Ciência Animal) - Curso de Pós-graduação em Ciência Animal, Universidade Federal de Goiás.

SILVA, N.S.; AZEVEDO, E.O.; CAMPOS, A.C. et al. Infecção congênita em cabritos por Mycoplasma agalactiae. Arq. Bras. Med. Vet. Zootec., v.66, n.2, p.631-634, 2014.

SILVA, N.S.; MARINHO, M.L.; AZEVEDO, E.O. et al. Tratamento alopático e homeopático em caprinos com agalaxia contagiosa: estudo comparativo. Archives of Veterinary Science, v.18, n.4, p.57-64, 2013. 